\title{
PRELIMINARY PROSPECTS OF A CARNOT-BATTERY BASED ON A SUPERCRITICAL CO2 BRAYTON CYCLE
}

\author{
Karin Rindt*, FrantišEK HrdliČKa, VÁClaV NovotnÝ
}

\author{
Czech Technical University in Prague, Faculty of Mechanical Engineering, Department of Energy Engineering, \\ Technická 4, 16607 Prague 6, Czech Republic \\ * corresponding author: karin.edel@fs.cvut.cz
}

\begin{abstract}
As a part of the change towards a higher usage of renewable energy sources, which naturally deliver the energy intermittently, the need for energy storage systems is increasing. For the compensation of the disturbance in power production due to inter-day to seasonal weather changes, a long-term energy storage is required. In the spectrum of storage systems, one out of a few geographically independent possibilities is the use of heat to store electricity, so-called Carnot-batteries. This paper presents a Pumped Thermal Energy Storage (PTES) system based on a recuperated and recompressed supercritical $\mathrm{CO}_{2}$ Brayton cycle. It is analysed if this configuration of a Brayton cycle, which is most advantageous for supercritical $\mathrm{CO}_{2}$ Brayton cycles, can be favourably integrated into a Carnot-battery and if a similar high efficiency can be achieved, despite the constraints caused by the integration. The modelled PTES operates at a pressure ratio of 3 with a low nominal pressure of $8 \mathrm{MPa}$, in a temperature range between $16^{\circ} \mathrm{C}$ and $513{ }^{\circ} \mathrm{C}$. The modelled system provides a round-trip efficiency of $38.9 \%$ and was designed for a maximum of $3.5 \mathrm{MW}$ electric power output. The research shows that an acceptable round-trip efficiency can be achieved with a recuperated and recompressed Brayton Cycle employing supercritical $\mathrm{CO}_{2}$ as the working fluid. However, a higher efficiency would be expected to justify the complexity of the configuration.
\end{abstract}

KeYwords: Pumped thermal energy storage (PTES), Carnot-battery, power-to-heat-to-power (P2H2P), supercritical $\mathrm{CO}_{2}$ cycle, Brayton cycle, heat exchange, pinch-point analysis.

\section{INTRODUCTION}

As the demand for renewable energy is increasing, so is the importance of its reliability. Unfortunately, the availability of energy from renewable sources and the electricity demand are usually not corresponding. The majority of renewable energy is obtained from so-called variable renewable energy sources (VRES), such as the solar radiation and wind, which the electric grid could handle, up to a maximum integration of $10 \%$, without any further changes [1]. The variation of hourly wind speed as well as the solar radiation compared to the feed-in, at the example of Nuremberg in Germany, can be visually compared in Figure 1 and Figure 2 This gives us an idea of the fluctuation of "available weather" and energy demand throughout a day. For this purpose, Figure 1 also shows the variation of the wind by highlighting its minimum and maximum values (at the different hours of the day throughout the year). The wind speed and solar radiation data are obtained from the MERRA database $\left[25^{1}\right]^{1}$, and the feed-in values from a local energy supplier called N-ERGIE [6].

These kinds of inequalities of supply and demand can be observed worldwide and throughout the whole year, also requiring shifting the energy between dif-

\footnotetext{
${ }^{1}$ The data from the MERRA database was, with a kind permission, obtained from Prof. Dr.-Ing. Matthias Popp, Burgstraße 19, D-95632 Wunsiedel, Germany and processed with an Excel-Tool (version 18.03.2016).
}

ferent seasons of the year. To tackle this problem, besides focusing on making the energy production as flexible as possible, energy storages are about to become of great importance in the change to a decarbonised future, as also stated by the International Energy Agency (IEA) [8].

Energy storage can also be an enabler for making VAES power plants like a Concentrated Solar Power (CSP) more competitive to traditional, fossil fuel burning power plants [9]. A thermal storage, directly integrated into the power cycle, can replace the Sun as a source of thermal energy when it is cloudy and allow the CSP plant to deliver energy more continuously and reliably. With a competitive solution like this, places with a high availability of solar radiation, for example Western China, could effectively use the Sun instead of a fossil fuel power plant, even if the interest would be more of an economic nature, rather than the protection of the environment.

In the spectrum of storage systems, the thermal energy storage (TES) is one out of a few possibilities how to store energy environmentally friendly and geographically independently. The pumped thermal energy storage (PTES), proposed in this paper, is also called Carnot-battery, Electro-Thermal Energy storage ETES or Pumped Heat Energy Storage PHES 2 The principle is described schematically in Figure 3

\footnotetext{
${ }^{2}$ Not to be confused with PHS (Pumped Hydro Storage).
} 


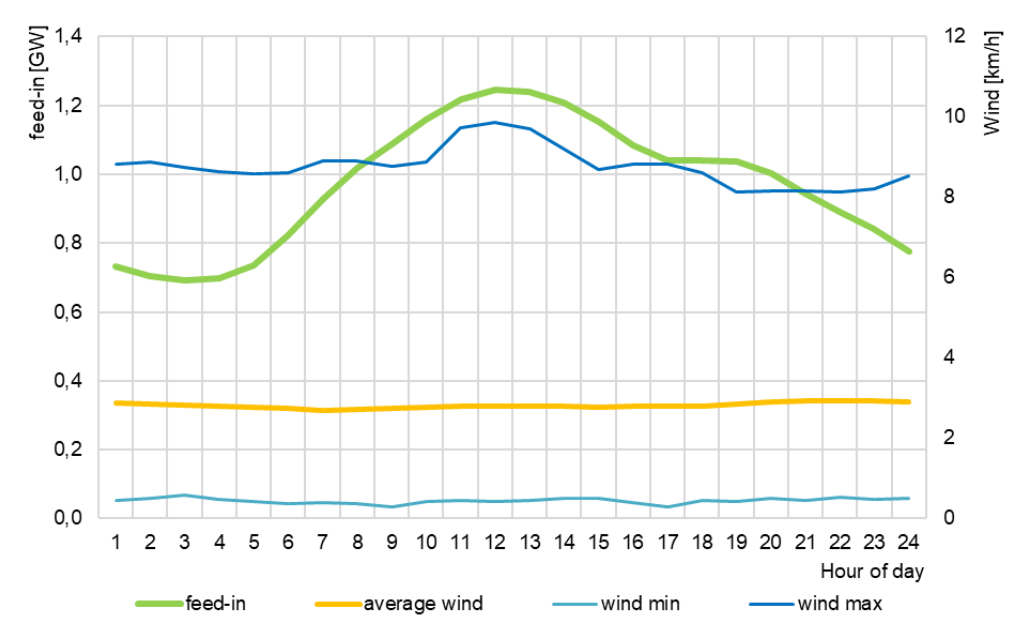

FigURE 1. Intraday load curve network supply and wind speed in Nuremberg, Germany, 2015 [6, 7].

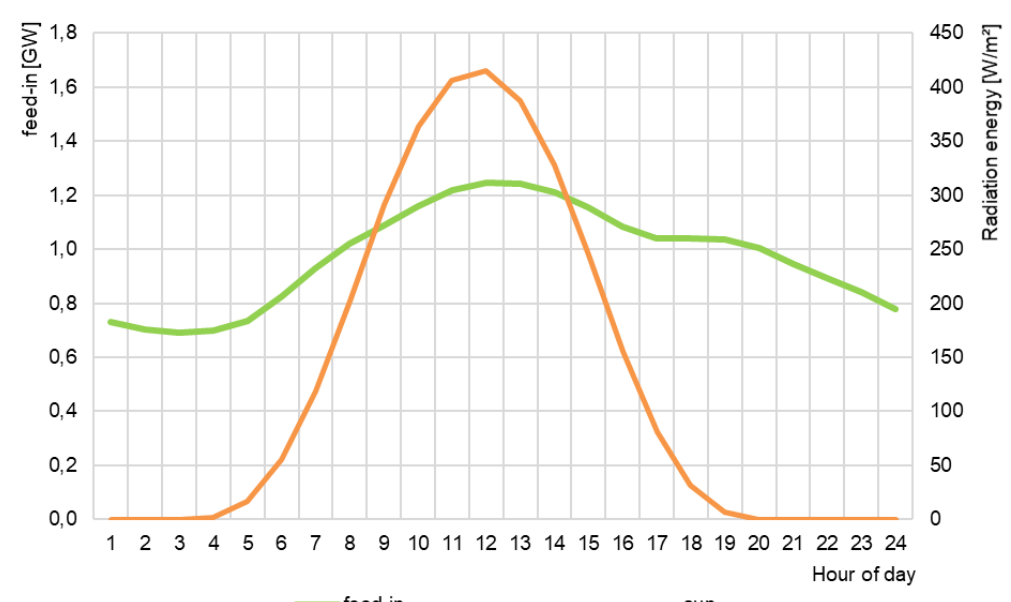

FiguRE 2. Intraday load curve network supply and solar radiation in Nuremberg, Germany, 2015 [6] 7.

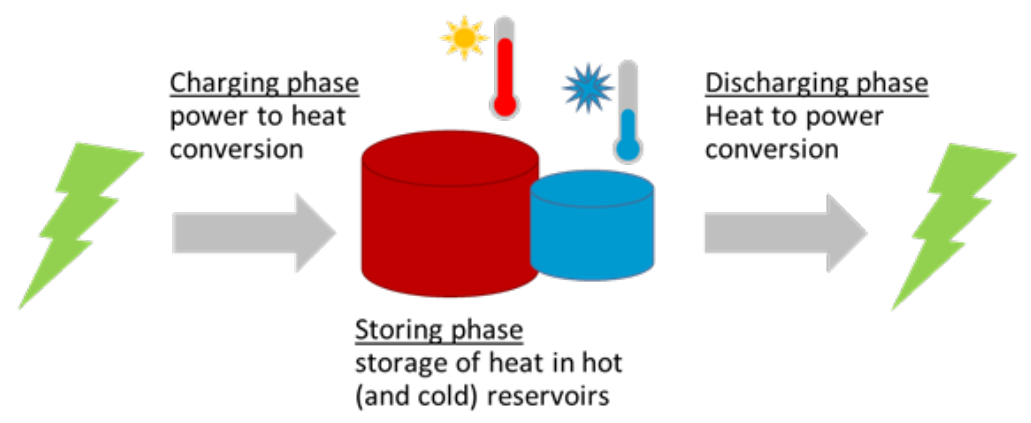

Figure 3. Principle of a Carnot-battery (modified from [10]). 


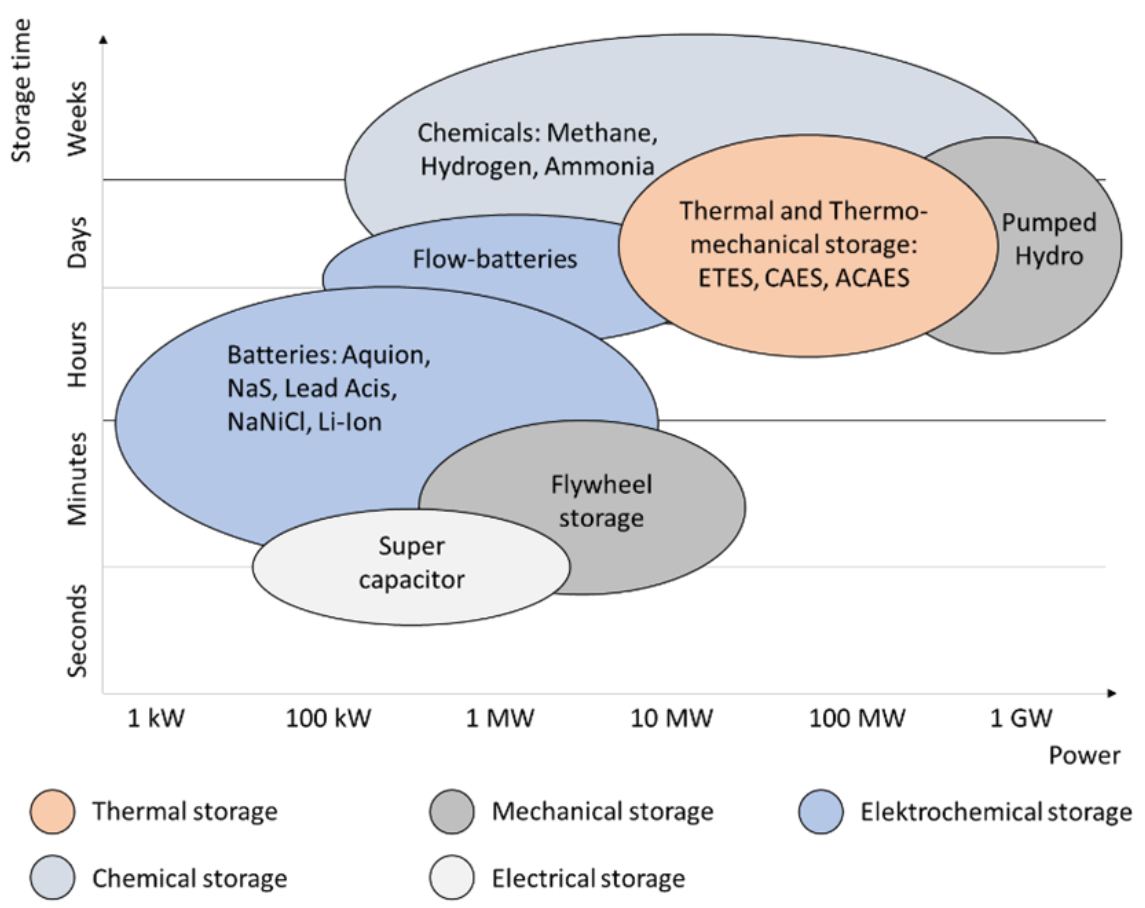

Figure 4. Comparison between different storage technologies (modified from [11, 12]).

The potential of different storage principles is visualised in Figure 4. Electro-Thermal Energy Storage (ETES) is rated as a technology feasible for longer storage times and higher power. Especially due to the possible storage time of several hours and days, it is feasible for handling the offset between the supply and the demand caused by the unstable nature of renewable energies sources like wind and solar radiation (as can be seen in Figure 1 and Figure 21. However, it is still in its concept phase [1], with the first prototypes being tested.

By 2020, several Carnot-battery pilot plants have been operated successfully. The Argon-based Brayton Cycle with a power of $150 \mathrm{~kW}$ (600 kWh electric) of the Newcastle University, built with the help of the company Isentropic Ltd. in the United Kingdom, is deploying reciprocating devices. The system has a round-trip efficiency of $60 \%$ to $65 \%$ [13] and is based on the theoretical concept by Howes [14]. SIEMENS Gamesa built a PTES pilot in Hamburg, Germany, which went into operation in summer 2019 [15-17]. They use an electric heater to heat air that is blown through a packed bed storage, thus charging it. For retrieving the power from the system, the thermal energy can be used to generate steam for a conventional Rankine cycle. The maximum electrical output power is then $1.5 \mathrm{MW}$, while the storage has a capacity of $30 \mathrm{MWh}$, with a round-trip efficiency of about $45 \%$ [810. Furthermore, two thermally integrated PTES (TI-PTES) with a heat-pump/organic Rankine cycle in a lab-scale were built in Liege, Belgium [18. Utilising waste thermal energy at $75^{\circ} \mathrm{C}$ as the cold source for the heat pump, a round-trip efficiency of $100 \%$ is reached [18, 19]. A liquid-air energy storage (LAES) with an $8 \%$ round-trip efficiency from the company Highview Power delivering $350 \mathrm{~kW}$ (2.5 MWh) was tested from 2011 to 2014 in Greater London [20, 21]. In addition, there are several other projects of Carnotbattery pilot plants already under development, in construction or being tested.

\section{2. $\mathrm{CO}_{2}$ AS WORKING FLUID FOR PTES CYCLES}

$\mathrm{CO}_{2}$ is an interesting candidate as a working fluid for PTES systems, because of its critical point at nearly ambient temperature and high densities. The low temperature is good for the rejection of thermal energy in a Brayton cycle 23 . The high density results in a comparably low compression work and high power density, which results in a small turbomachinery [24]. Additionally, it is widely available, inexpensive and nontoxic 24. Problems with $\mathrm{CO}_{2}$ are that it is highly diffusive, enhances corrosion of surrounding materials, leads to a rapid depressurisation and is very sensitive to small changes in pressure or temperature near the critical point [24]. Additionally, the specific heat capacity of carbon dioxide strongly varies, leading to high changes in the temperature difference between the hot and cold fluid in heat exchangers, which can cause the minimal temperature difference to be not at an inlet or exit, but inside the heat exchanger, which is called a pinch-point problem [23. As compared to cycles running with other working fluids, $\mathrm{CO}_{2}$ cycles are not so widely tested and used yet, which can lead to possible problems, but also offers a great potential.

Most proposed PTES systems, which employ $\mathrm{CO}_{2}$ as the working fluid, are based on transcritical Rankine 


\begin{tabular}{cccccc}
\hline Name & Formula & Molecular weight & Critical temperature & Critical pressure & Critical density \\
\hline Carbon dioxide & $\mathrm{CO}_{2}$ & $44.01 \mathrm{~kg} / \mathrm{mol}$ & $31.03{ }^{\circ} \mathrm{C}$ & $7.383 \mathrm{MPa}$ & $466 \mathrm{~kg} / \mathrm{m} 3$ \\
\hline
\end{tabular}

TABle 1. Physico-chemical properties of $\mathrm{CO}_{2}[22$.

cycles, reaching a round-trip efficiency between $40.9 \%$ and $68.6 \%$ 25 29]. Only McTigue et al. proposed a supercritical $\mathrm{CO}_{2}$ Brayton cycle, reaching a $60.4 \%$ round-trip efficiency with a low-temperature cycle and $78.4 \%$ in a high-temperature cycle 30 . A very different approach is the transcritical isothermal Rankine cycle by Kim et al., using a double-acting liquid piston system with a direct heat transfer to the storage media water, reaching a $68.6 \%$ round-trip efficiency [31].

For the proposed transcritical $\mathrm{CO}_{2}$ Rankine cycles, the pinch-point problem is usually solved by using multiple hot storage tanks, using an indirect heat transfer to (mostly pressurised) water tanks [25, 26, 32. For Ayachi et al. 28, who are using a ground storage, the heat transfer is directly between the $\mathrm{CO}_{2}$ and the solid storage material through which it is flowing (direct, passive multi-tube packed bed storage). Their pinch-point considerations are directly connected with the overall storage design. Steinmann et al. [29]point out that it is generally impossible to achieve a mean temperature difference of 5 to $10 \mathrm{~K}$ between a single pressurised water storage and the $\mathrm{CO}_{2}$ while still having a constant mass flow and a significant heat transfer (temperature difference) in the heat exchanger. Unlike the before mentioned research, they choose to assume an ideal storage system, neglecting the pinchpoint problem, rather than coming up with a possible solution. McTigue et al. designed a simple, nonrecuperated Brayton cycle [30, even though they're mentioning, that recuperation would be feasible due to the high-temperature difference between the compression and the expansion.

Due to the high potential of $\mathrm{CO}_{2}$ in its supercritical state, this paper investigates a new layout of a Brayton $\mathrm{sCO}_{2}$ PTES. The proposed cycle is recompressed and employs a double recuperation because this layout is reaching the highest efficiencies for $\mathrm{sCO}_{2}$ cycles and, generally, has a great potential for recuperation, as also stated by McTigue et al. [30, whereas other research focused on transcritical $\mathrm{CO}_{2}$ Cycles or simple non-recuperated supercritical $\mathrm{CO}_{2}$ cycles [33, 34. The paper will determine if this layout is favourable for a Carnot Battery and how the boundary conditions limit the power cycle performance (e.g., how the Carnot-batteries storage temperatures, flow rates of the working fluid and the storage material limit the options of cycle configuration and influence one another). The effects of different operating temperatures and pressure ratios as well as various temperature differences of the heat exchangers and efficiencies of turbines and compressors were analysed. The key in- puts are presented together with the best combination of parameters in the Section 4

\section{Concept of a supercritical $\mathrm{CO}_{2}$ BRAYTON CYCLE WITH HOT AND COLD LIQUID STORAGE}

\subsection{DeSCRIPTION OF THE HOT AND COLD STORAGE}

The proposed supercritical $\mathrm{CO}_{2}$ Brayton cycle has a hot and cold two-tank liquid storage. For the discharging cycle, a turbine and two compressors (one for recompression) are needed. The same principle applies to the charging cycle, where two turbine sections and one compressor are necessary. For the charging cycle, a heat exchanger to ambient air is necessary due to irreversibilities within the cycle. Furthermore, each configuration needs two heat exchangers for the recuperation. Two heat exchangers for transferring the thermal energy between the cycle and the storage tanks are used for the charging and discharging. Since the heat pump and the power cycle can employ the same pressure ratio due to the flexibility in mass flows through the recompression stage, it seems possible that some of the turbomachinery can be used in charging and discharging modes. Possible effects are not considered further.

Each storage consists out of two tanks, one contains the storage material at a high- temperature and the other one a material at a low-temperature. Within a tank, the storage material is kept at a constant temperature. Figure 5 shows the working principle of the two-tank storage. During the charging, the material from the colder tank of the hot storage is pumped through a heat exchanger, which is transferring the thermal energy from the cycle to the storage media. It is then stored in the second tank at a higher temperature. For the cold storage, the fluid is cooling down during the charging cycle, heating the cycle fluid. In the discharging phase, the fluid is pumped the other way around. The hot tank of the hot storage is emptying while the colder tank is filling up, and the level of fluid in the cold tank of the cold storage is decreasing while it is rising in the warmer tank. Through maintaining a constant flow between a charged and discharged tank of a storage, where both tanks maintain a constant temperature but vary only in the amount of stored material, the heat flux in the heat exchanger is constant. The constant heat flux is an advantage over packed beds, where the problem of a non-constant temperature output is a challenge faced in the cycle design. 


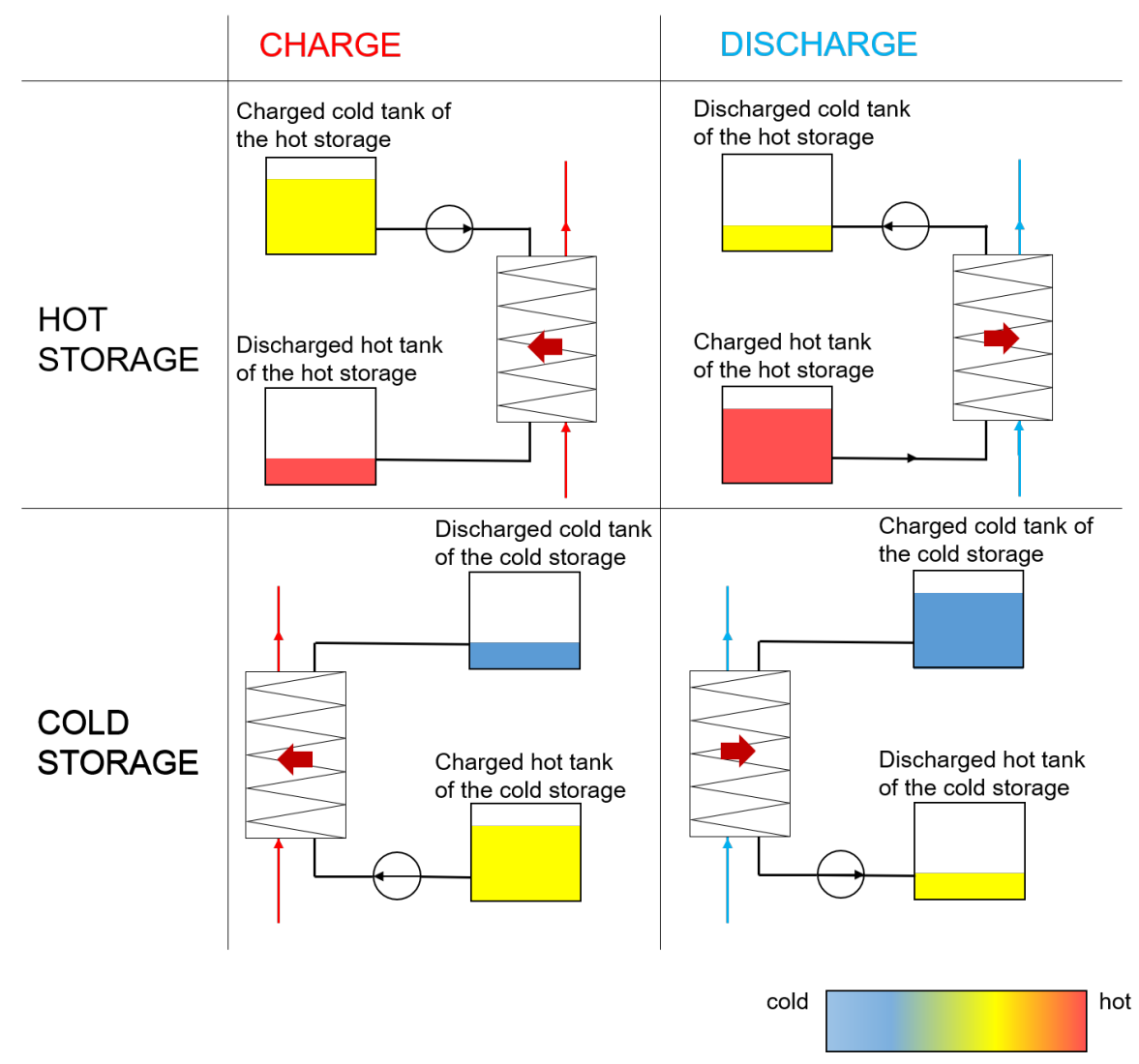

Figure 5. Scheme of the hot and cold two-tank storage.

The hot storage material is solar salt with the chemical composition of $60 \% \mathrm{NaNO}_{3}+40 \% \mathrm{KNO}_{3}$. It has a melting temperature of $221.04{ }^{\circ} \mathrm{C}$ and thermal stability up to $588.51^{\circ} \mathrm{C}[35$. The mean heat capacity for the operating temperatures of the hot storage is $1.518 \mathrm{~kJ} \mathrm{~kg}^{-1} \mathrm{~K}^{-1}[36$. The cold storage can work with a thermal oil such as THERMINOL 66 due to the lower temperatures (thermal stability up to $380^{\circ} \mathrm{C}$ ) 37. The mean heat capacity of the thermal oil at cold storage temperatures is $1.782 \mathrm{~kJ} \mathrm{~kg}^{-1} \mathrm{~K}^{-1}$. Self-discharge of the storages is neglected.

\subsection{Double RECUPERATED AND RECOMPRESSED BRAYTON CYCLE WITH $\mathrm{CO}_{2}$ AS WORKING FLUID}

The PTES is designed to deliver $10 \mathrm{MW}$ of thermal power (3.4 MW electric). Self-discharging of the storages, the pumps on the storage side and mechanical and electrical losses are neglected, while losses due to heat transfer were considered. A parameter variation as well as a pinch-point analysis were carried out to determine the best cycle performance.

\subsubsection{Cycle layout for charging the (hot) STORAGE}

In Figure 6 the layout of the charging cycle is shown. At a pressure ratio of 3 , the system is operating in a temperature range between $16^{\circ} \mathrm{C}$ and $513^{\circ} \mathrm{C}$. From point 1 to 2 , the $\mathrm{CO}_{2}$ is compressed to a pressure of $24 \mathrm{MPa}$, and between 2 and 3, the thermal energy is used for charging the hot storage, cooling down the fluid. The thermal energy at the lower temperature is recuperated between 3 and 4 . At point 4 , the mass flow is split to continue with the recuperation from 4 to 5 and expansion from 4 to 8 . After point 5, irreversibilities are dissipated to the environment in a heat exchanger between 5 and 6 . From 6 to 7 , the second portion of the working fluid is expanded back to $8 \mathrm{MPa}$ in the turbine and then heated from 7 to 8 by cooling down the cold storage. At point 8 , the flow is merged with the parallel expanded portion, and from 8 to 9 and 9 to 1 , heated with the recuperated thermal energy from 3 to 4 and 4 to 5 . By splitting the flow in point 4 and merging it in point 8 , the amount of heat transferred to the cold storage can be influenced.

\subsubsection{Cycle layout For Discharging the (HOT) STORAGE}

The layout for the discharging cycle can be seen in Figure 7. The upper and lower temperatures are given through the terminal temperature difference of $8 \mathrm{~K}$ between the working fluid and the hot storage during the charging and discharging. The pressure ratio for this cycle is 3 as well $(8 \mathrm{MPa} / 24 \mathrm{MPa})$. From state $\mathrm{A}$ to $\mathrm{B}$, the $\mathrm{CO}_{2}$ expands, with a following recuperation $\mathrm{B}$ to $\mathrm{C}$ and $\mathrm{C}$ to $\mathrm{D}$. At $\mathrm{D}$, the flow is split into a share, which is cooled by discharging the cold storage (D to E), compressed (E to F) and recuperated ( $\mathrm{F}$ to $\mathrm{G}$ ), with a part being directly recompressed 


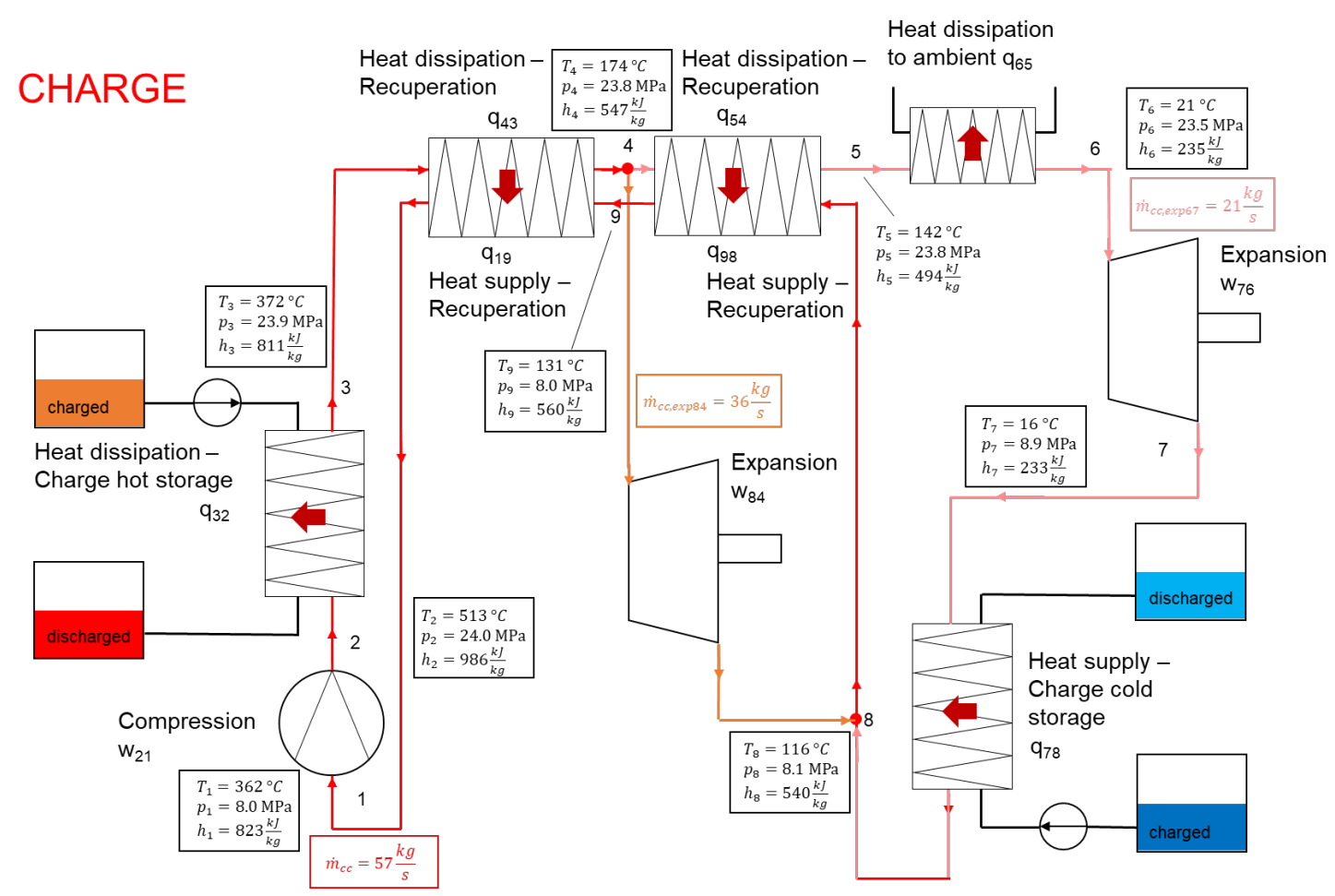

Figure 6. Double recuperated $\mathrm{sCO}_{2}$ Brayton Cycle as a heat pump with dual expansion (charging).

\section{DISCHARGE}

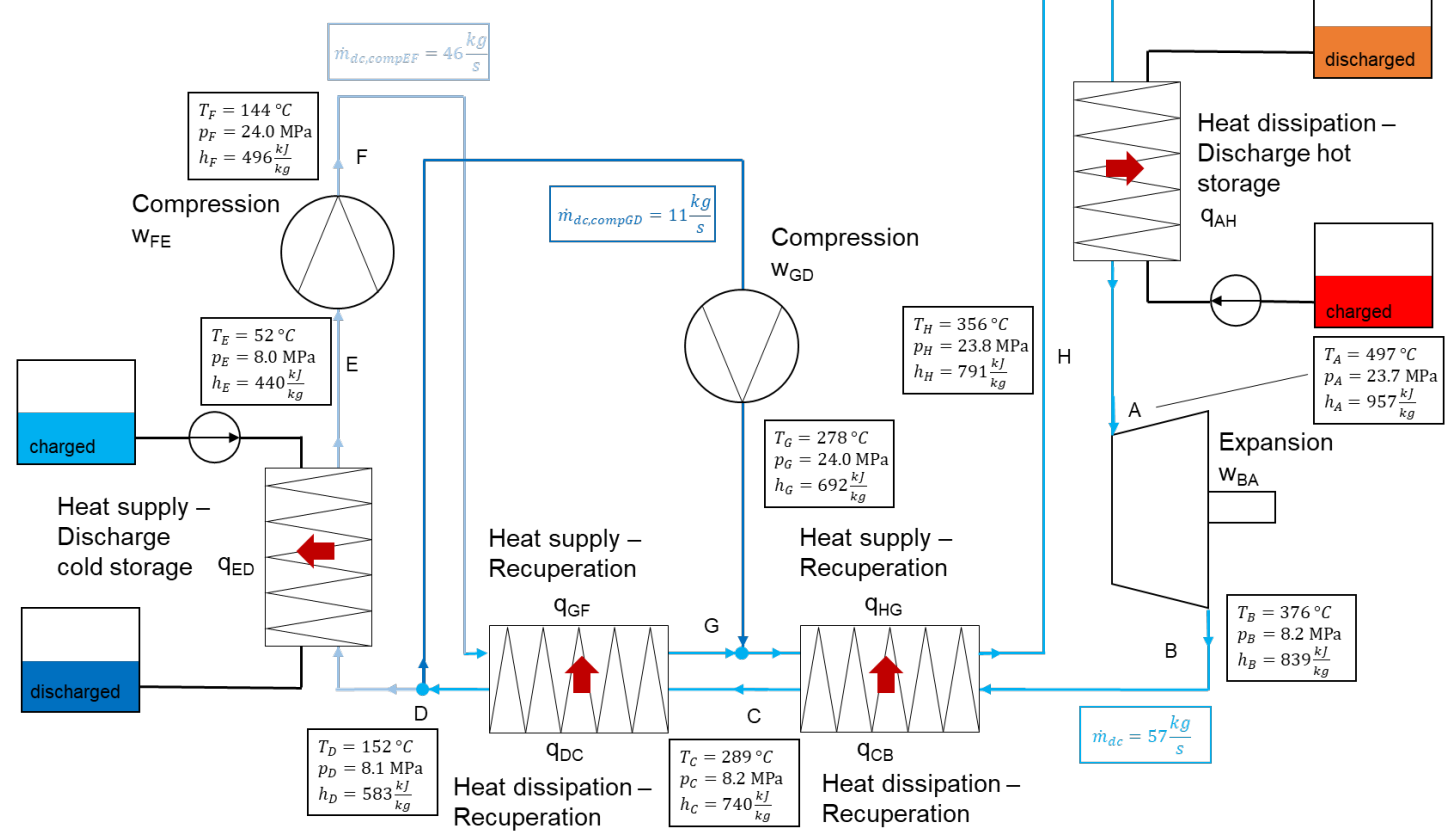

Figure 7. Double recuperated and recompressed $\mathrm{CO}_{2}$ Brayton Cycle (discharging). 


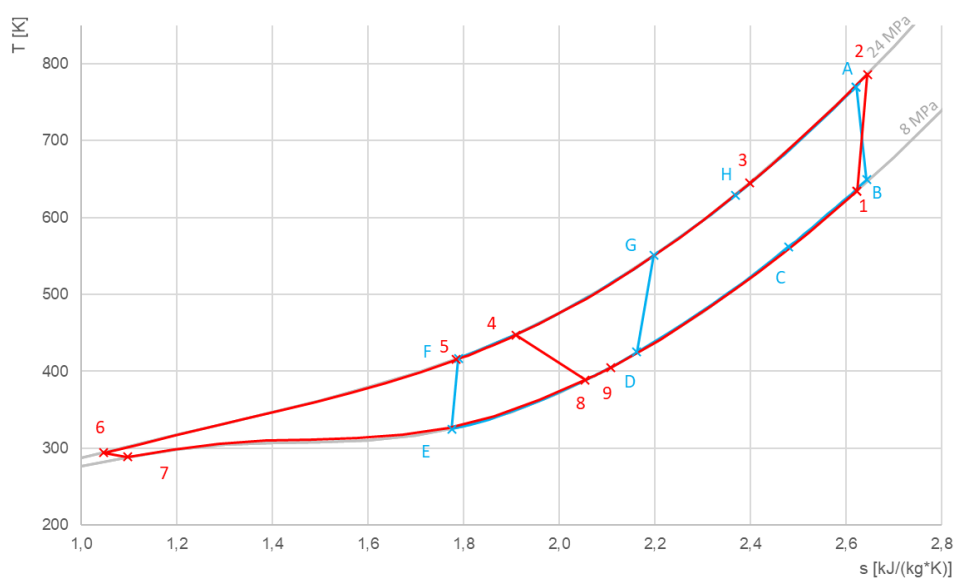

FIGURE 8. T-s diagram of the charging (red) and discharging (blue) of the proposed PTES with recuperated and recompressed $\mathrm{sCO}_{2}$ Brayton Cycle.

( $D$ to $G$ ) before being merged again in point $G$. The second heating with recuperation takes place from $\mathrm{G}$ to $\mathrm{H}$ and with the thermal energy from the hot storage from $\mathrm{H}$ to $\mathrm{A}$.

\subsubsection{THERMODYNAMIC MODEL}

Both the charging and discharging cycles are illustrated in Figure 8. The nominal value of the low pressure is $8 \mathrm{MPa}$ and therefore, close to the critical value. With the mentioned pressure ratio of 3 , the nominal high pressure is $24 \mathrm{MPa}$. The efficiency of the discharging cycle of the PTES system $\eta_{d c}$ is $34.9 \%$ (1), and the coefficient of performance of the heat pump (charging cycle) $C O P_{c c}$ of the PTES system is 1.11 2. All $\mathrm{CO}_{2}$ properties were retrieved from the REFPROP library 38 .

$$
\begin{aligned}
& \eta_{d c}=\frac{W_{n e t, d c}}{Q_{\text {hotstor }, d c}}= \\
& =\frac{W_{\text {exp }, A B}-W_{\text {comp }, E F}-W_{\text {comp }, D G}}{Q_{H A}} \\
& C O P_{c c}=\frac{Q_{\text {out }, \text { hotstor }, c c}}{W_{\text {net }, c c}}= \\
& =\frac{Q_{23}}{W_{\text {comp }, 12}-W_{\text {exp }, 67}-W_{\text {exp }, 48}}
\end{aligned}
$$

$W_{n e t}$ denotes the cycle work (net cycle work), $W_{\text {exp }}$ the expansion work and $W_{\text {comp }}$ the compression work, while $Q_{\text {hotstor }}$ and $Q_{\text {coldstor }}$ describe the heat flux between the cycle and the hot and cold storages, respectively. The indices $d c$ and $c c$ are further describing the discharging and charging cycles, while the numbers (for the charging cycle) and letters (for the discharging cycle) specifically describe between which states the change takes place.

The round-trip efficiency $\eta_{r t}$ of the proposed system is $38.9 \%$ and calculated with the net work ratio of charging and discharging cycles (3), or expressed differently with (1) and (2), by multiplying the COP of the heat pump and the efficiency of the heat engine (4).

$$
\begin{gathered}
\eta_{r t}=\frac{W_{n e t, d c}}{W_{n e t, c c}}= \\
=\frac{W_{\text {exp }, A B}-W_{c o m p, E F}-W_{c o m p, D G}}{W_{c o m p, 12}-W_{e x p, 67}-W_{\exp , 48}} \\
\eta_{r t}=C O P_{c c} \cdot \eta_{d c}
\end{gathered}
$$

Table 2 lists the isentropic efficiencies of the turbomachinery, the work and the heat transfer rates within and over the boundaries of the cycle. The heat flux from the hot storage to the cycle during the discharging is set by the power of the system $\dot{\mathrm{Q}}_{\text {system }}=3.4 \mathrm{MW}$ and the efficiency of the discharging cycle (5). Furthermore, the total mass flow rate $\dot{m}$ is calculated with the enthalpy difference $\Delta h$ of the storage 6 .

$$
\begin{gathered}
\dot{Q}_{\text {hotstor }}=\frac{\dot{Q}_{\text {system }}}{\eta_{d c}} \\
\dot{m}_{d c}=\dot{Q}_{\text {hotstor }} \cdot \Delta h_{H A}
\end{gathered}
$$

Around a mass flow ratio $\dot{m}_{d c, \text { maincomp }} / \dot{m}_{d c \text {, total }}$ of 0.8 , the pinch-points within and between the charging and discharging cycles are in the desired range. Together with the enthalpy difference from $\mathrm{D}$ to $\mathrm{E}$, the heat flux from the cycle to the cold storage fluid is calculated (7)

$$
\dot{Q}_{\text {coldstor }}=\dot{m}_{d c, \text { maincomp }} \cdot \Delta h_{D E}
$$

The mass flow on the storage side, between the two tanks, is calculated in the same manner but is a little bit lower due to the irreversibilities in the heat 


\begin{tabular}{|c|c|c|c|c|c|}
\hline \multicolumn{6}{|c|}{ Temperatures and pressures } \\
\hline & $\mathrm{T}_{\text {low }}$ & 16 & {$\left[{ }^{\circ} \mathrm{C}\right]$} & & \\
\hline & $\mathrm{T}_{\text {high }}$ & 513 & {$\left[{ }^{\circ} \mathrm{C}\right]$} & & \\
\hline & p nom,low & 8 & {$[\mathrm{MPa}]$} & & \\
\hline & Pressure ratio & 3 & {$[-]$} & & \\
\hline \multicolumn{3}{|c|}{ Mass flow charging cycle } & \multicolumn{3}{|c|}{ Mass flow discharging cycle } \\
\hline$\dot{\mathrm{m}}_{\text {total }, \mathrm{cc}}$ & 56.9 & {$[\mathrm{~kg} / \mathrm{s}]$} & $\dot{\mathrm{m}}_{\text {total,dc }}$ & 56.9 & {$[\mathrm{~kg} / \mathrm{s}]$} \\
\hline Ratio $\dot{\mathrm{m}}$ & 0.8 & {$[-]$} & Ratio $\dot{\mathrm{m}}$ & 0.4 & {$[-]$} \\
\hline \multicolumn{6}{|c|}{ Efficiency compressor and turbine } \\
\hline & & 0.9 & {$[-]$} & & \\
\hline \multirow{2}{*}{\multicolumn{2}{|c|}{$\eta_{\exp }$}} & 0.9 & {$[-]$} & & \\
\hline & & \multicolumn{2}{|c|}{ Terminal temperature difference } & \multicolumn{2}{|c|}{ Pinch Point } \\
\hline \multicolumn{2}{|c|}{ Cold storage } & 18 & {$[\mathrm{~K}]$} & 7.5 & {$[\mathrm{~K}]$} \\
\hline \multirow{2}{*}{\multicolumn{2}{|c|}{$\begin{array}{c}\text { Hot storage } \\
\text { Recuperation }\end{array}$}} & 8 & {$[\mathrm{~K}]$} & 7.4 & {$[\mathrm{~K}]$} \\
\hline & & 8 & {$[\mathrm{~K}]$} & 8 & {$[\mathrm{~K}]$} \\
\hline \multicolumn{6}{|c|}{ Cycle efficiency } \\
\hline \multirow{3}{*}{\multicolumn{2}{|c|}{$\begin{array}{c}\mathrm{COP}_{\mathrm{cc}} \\
\eta_{\mathrm{dc}} \\
\eta_{\text {overall }}\end{array}$}} & 1.10 & {$[-]$} & & \\
\hline & & 0.342 & {$[-]$} & & \\
\hline & & 0.378 & {$[-]$} & & \\
\hline Charging cycle & \multicolumn{5}{|c|}{ Discharging cycle } \\
\hline $\mathrm{W}_{\text {comp }, 12}$ & 9294 & {$[\mathrm{~kW}]$} & $\mathrm{W}_{\exp , \mathrm{AB}}$ & -7249 & {$[\mathrm{~kW}]$} \\
\hline$W_{\exp , 48}$ & -272 & {$[\mathrm{~kW}]$} & $\mathrm{W}_{\text {comp, EF }}$ & 2530 & {$[\mathrm{~kW}]$} \\
\hline $\mathrm{W}_{\exp , 67}$ & -33 & {$[\mathrm{~kW}]$} & $\mathrm{W}_{\text {exp,DG }}$ & 1225 & {$[\mathrm{~kW}]$} \\
\hline $\mathrm{Q}_{\text {in,coldstor } 78}$ & 6506 & {$[\mathrm{~kW}]$} & Qout,coldstor,DE & -6506 & {$[\mathrm{~kW}]$} \\
\hline Qout,hotdstor,23 & -10000 & {$[\mathrm{~kW}]$} & $Q_{\text {in,hotstor,HA }}$ & 10000 & {$[\mathrm{~kW}]$} \\
\hline$Q_{a m b, 56}$ & -5495 & [kW] & $\mathrm{Q}_{\text {recup }, \mathrm{BC}}$ & -5664 & {$[\mathrm{~kW}]$} \\
\hline $\mathrm{Q}_{\text {recup }, 34}$ & -14987 & {$[\mathrm{~kW}]$} & $\mathrm{Q}_{\text {recup,GH }}$ & 5664 & {$[\mathrm{~kW}]$} \\
\hline $\mathrm{Q}_{\text {recup }, 91}$ & 14987 & {$[\mathrm{~kW}]$} & $\mathrm{Q}_{\text {recup }, \mathrm{CD}}$ & -8876 & {$[\mathrm{~kW}]$} \\
\hline $\mathrm{Q}_{\text {recup }, 45}$ & -1139 & {$[\mathrm{~kW}]$} & $\mathrm{Q}_{\text {recup }, \mathrm{FG}}$ & 8876 & {$[\mathrm{~kW}]$} \\
\hline Qrecup, 89 & 1139 & {$[\mathrm{~kW}]$} & & & \\
\hline$W_{\text {net,cc }}$ & 8989 & {$[\mathrm{~kW}]$} & $W_{\text {net,dc }}$ & -3494 & {$[\mathrm{~kW}]$} \\
\hline
\end{tabular}

TABLE 2. Thermal model key inputs and results for the proposed PTES.

exchanger. The effectiveness of the heat exchangers is represented by a minimum pinch-point between the storage side and the cycle. The enthalpy difference on the storage side then results from the corresponding temperatures and the heat capacity of the storage material.

The minimum amount of stored thermal energy (8) and storage material (9) for the hot and cold storage, respectively, can be found by multiplying the mass flow rate with the storage discharging time.

$$
\begin{gathered}
Q_{\text {stor }}=\dot{Q}_{\text {stor }} \cdot t_{\text {discharge }} \\
m_{\text {stor }}=\dot{m}_{\text {stor }, d c} \cdot t_{\text {discharge }}
\end{gathered}
$$

Five hours were chosen for the duration of charging and discharging as this is a typical wind farm production time [39].

\subsubsection{EFFECT OF DIFFERENT SYSTEM PARAMETERS ON THE SYSTEM'S ROUND-TRIP EFFICIENCY}

To get a full use of the positive effects of $\mathrm{CO}_{2}$ close to its critical pressure, a low pressure of $8 \mathrm{MPa}$ was chosen. In Figure 9 it can be seen that the roundtrip efficiency $\left(\eta_{r t}\right)$ is higher with a higher pressure ratio of the discharging cycle and a lower pressure ratio in the charging cycle. However, pressure ratios lower than 3 in the charging cycle and lower than 4, with a discharging cycle pressure ratio of 4 , as well as pressure ratios during discharging higher than 4, are not possible in this PTES system, because the minimum temperature differences would get violated. The best combination is a pressure ratio of 3 for the charging as well as the discharging cycle.

A greater difference between the minimum and maximum temperatures results in a higher round-trip efficiency, as to be expected. $10^{\circ} \mathrm{C}$ are, therefore, suggested as the minimum temperature of the ideal PTES 


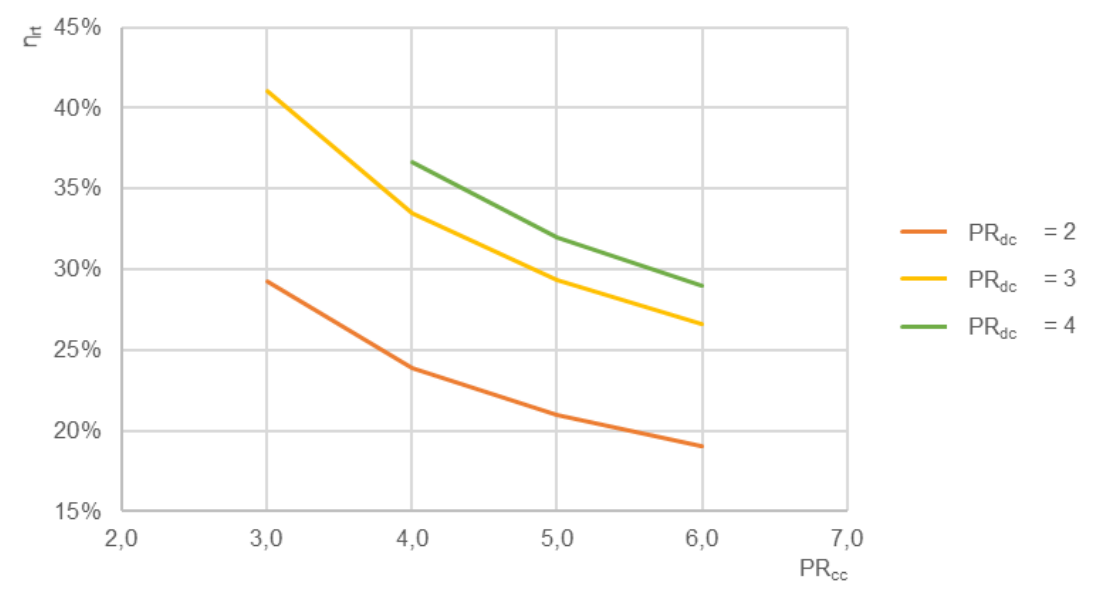

FIGURE 9. Effect of the pressure ratios of charging and discharging cycles on the system's round-trip efficiency.

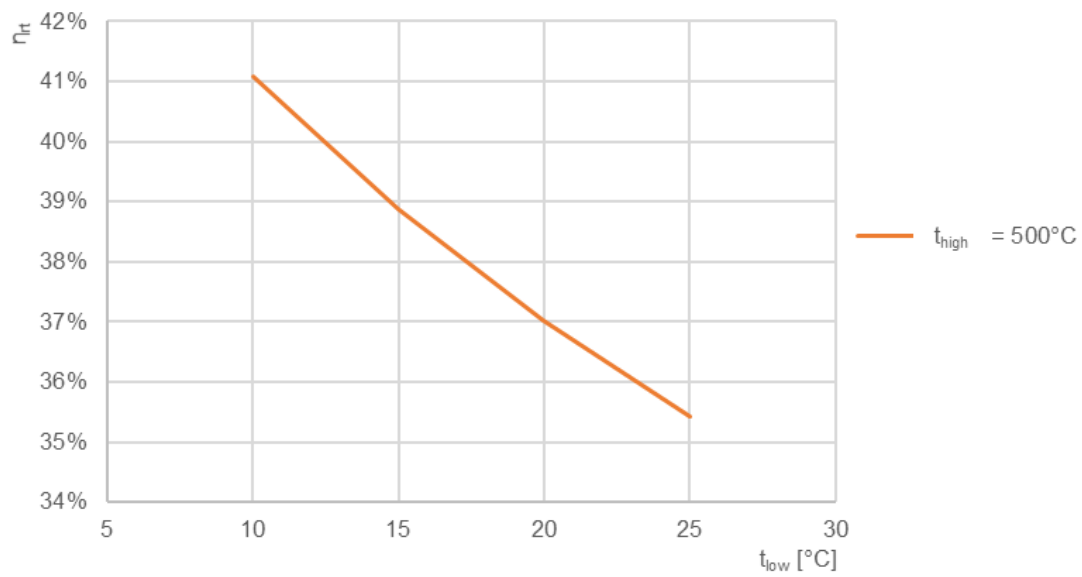

FigURE 10. Effect of the low temperature on the system's round-trip efficiency (with a high temperature of $500^{\circ} \mathrm{C}$ ).

$\left(t_{\text {low }}\right)$. The resulting minimum temperature of the cycle fluid for the rejection of thermal energy to ambient is $20^{\circ} \mathrm{C}$. Figure 10 shows that a raise in the cycle's low temperature would cause a drastic drop in the system's round-trip efficiency. The PTES is then proposed with a maximum temperature of $500^{\circ} \mathrm{C}\left(t_{\text {high }}\right)$, which is the limit for many materials that could be used for the storage containers, turbomachinery, and storage materials.

In Figure 11, it can be seen that with temperatures greater $600^{\circ} \mathrm{C}$, nearly $50 \%$ efficiency can be achieved. At temperatures as high as this, storage materials like the solar salt mixture $40 \% \mathrm{NaNO}_{2}+7 \% \mathrm{NaNO}_{3}+$ $53 \% \mathrm{KNO}_{3}$ with a working range between $142.24^{\circ} \mathrm{C}$ (melting point) and $630.97^{\circ} \mathrm{C}$ and a heat capacity of $1439 \mathrm{~J} / \mathrm{kgK}$, as proposed for CSP plants by Fernández et al., could be used 35].

The effect of the isentropic efficiencies of the compressors and expanders is also clear. In Figure 12 , the change of the round-trip efficiency with the isentropic compressor efficiency $\left(\eta_{\text {comp }}\right)$ is shown. Once with a constant isentropic expander efficiency of 0.9 $\left(\eta_{\text {exp }}=0.9\right)$, and one time with an equal efficiency for all turbomachinery $\left(\eta_{\text {comp }}=\eta_{\text {exp }}\right)$. The latter is a very simplified approach because, generally, the turbine's efficiency can be expected to be much higher than the compressor's efficiency. It is, though, certain that the isentropic efficiency of the turbomachinery has a great impact on the system's round-trip efficiency.

The last analysed impact are the temperature differences of the various heat exchangers of the system. A special focus was also on the pinch-point problem, as investigated for the best configuration of the cycle in the next chapter 3.2.5). Generally, a smaller temperature difference (e.g. higher effectiveness of the heat exchangers) means a higher round-trip efficiency of the system, as can be seen in Figure 13. Besides the case, where the terminal temperature difference of the cold storage heat exchanger and the recuperator is each $5 \mathrm{~K}\left(t d T_{\text {coldst }}=5 ; t d T_{\text {recup }}=5\right.$, yellow line), the temperature difference between the heat exchanger and the cold storage is shown on the $\mathrm{x}$-axis. In the mentioned case $\left(t d T_{\text {coldst }}=5 ; t d T_{\text {recup }}\right.$ $=5$ ), it is the temperature difference of the hot storage heat exchanger $\left(t d T_{\text {hotst }}\right)$ instead. All variations are displayed in this one diagram to allow an easy visual identification of the best combination. The temperature difference compared in the diagram is the terminal temperature difference at the two ends of the heat exchanger and is, therefore, not trans- 


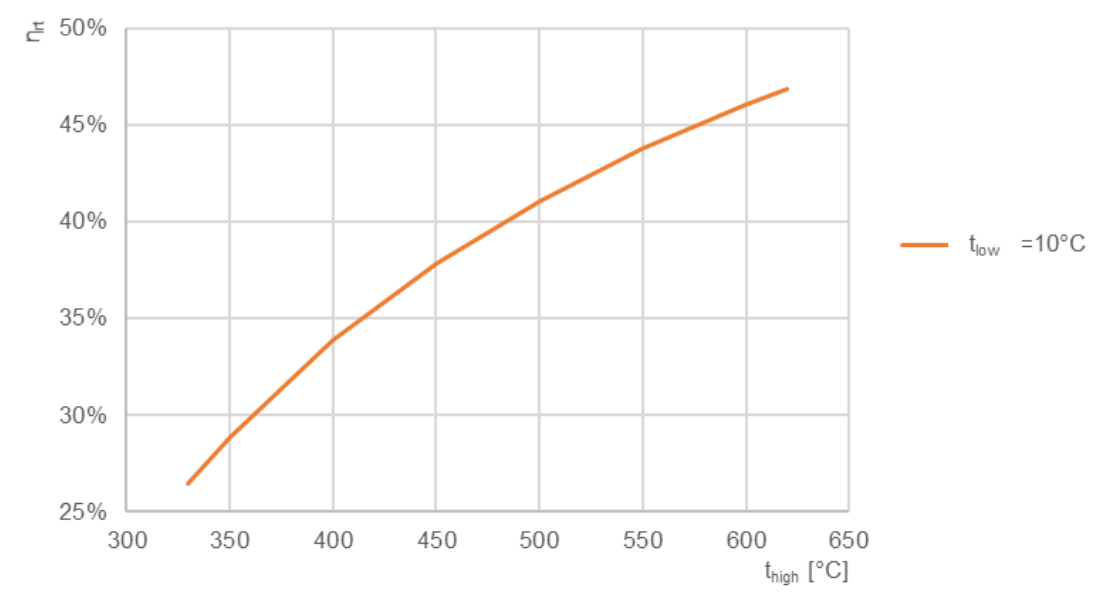

FIGURE 11. Effect of the high temperature on the system's round-trip efficiency (with a low temperature of $10^{\circ} \mathrm{C}$ ).

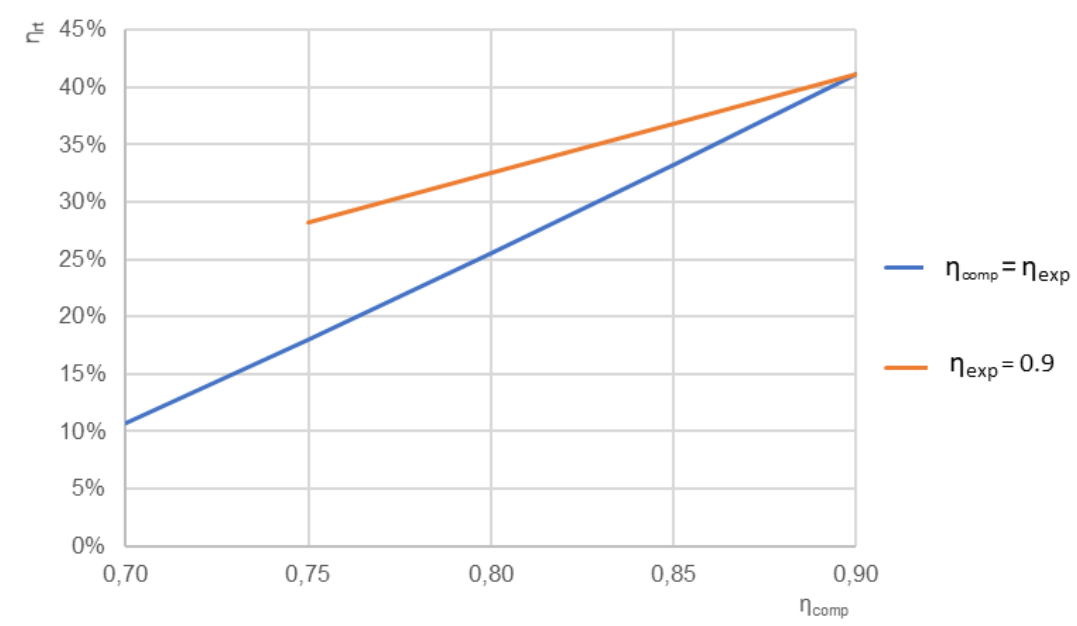

FigURE 12. Effect of the isentropic efficiencies of compressor and expander on the system's round-trip efficiency.

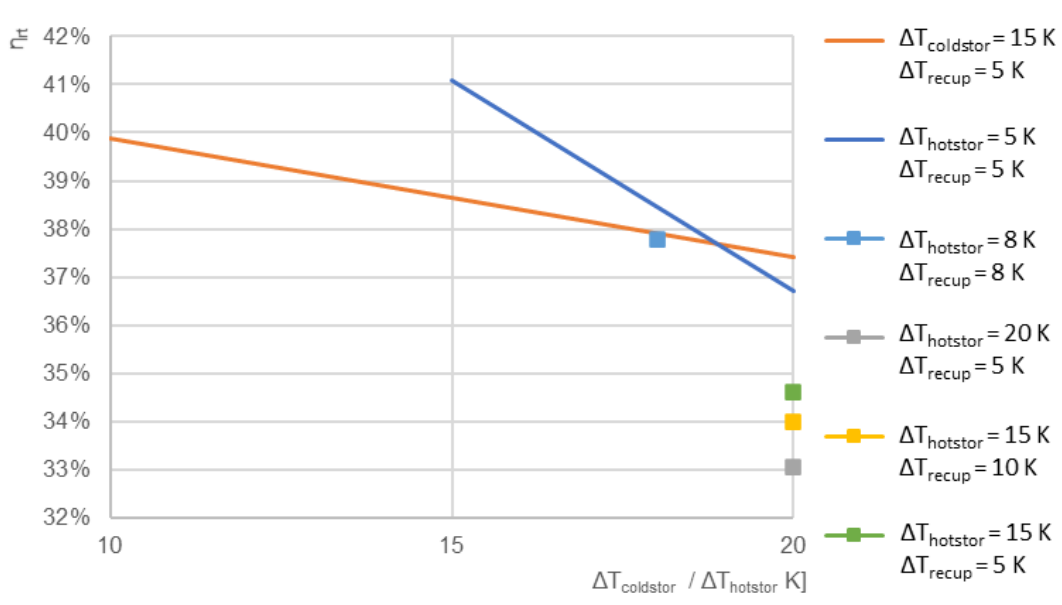

FIGURE 13. Effect of the temperature differences at the heat exchanger ends on the system's round-trip efficiency. 


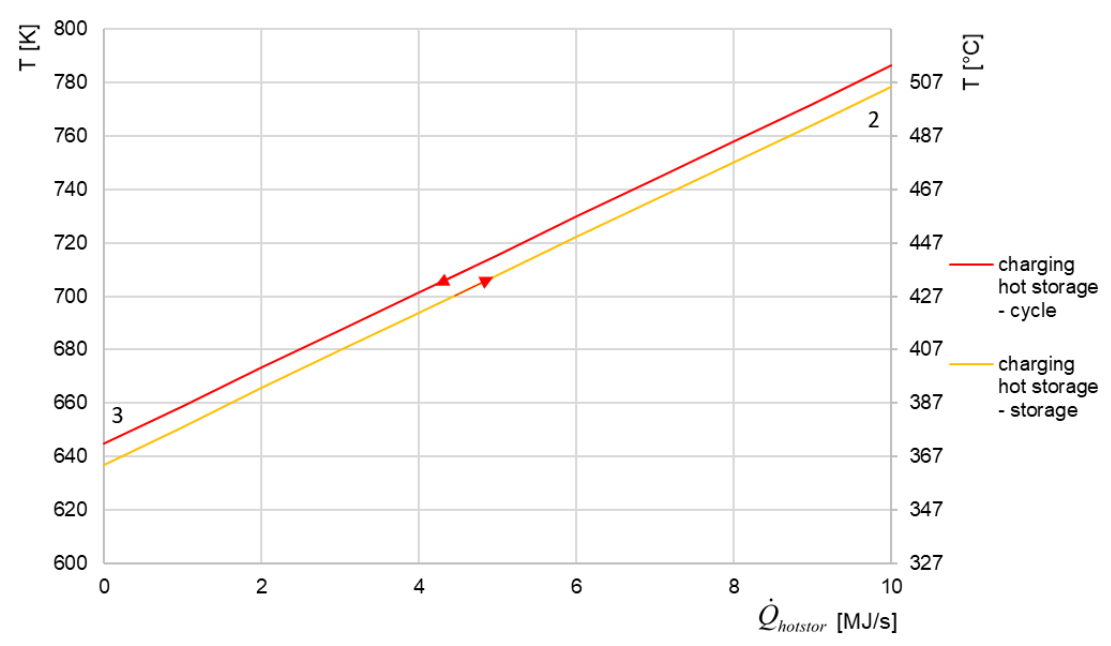

Figure 14. Heat transfer from the (charging) cycle to the hot storage.

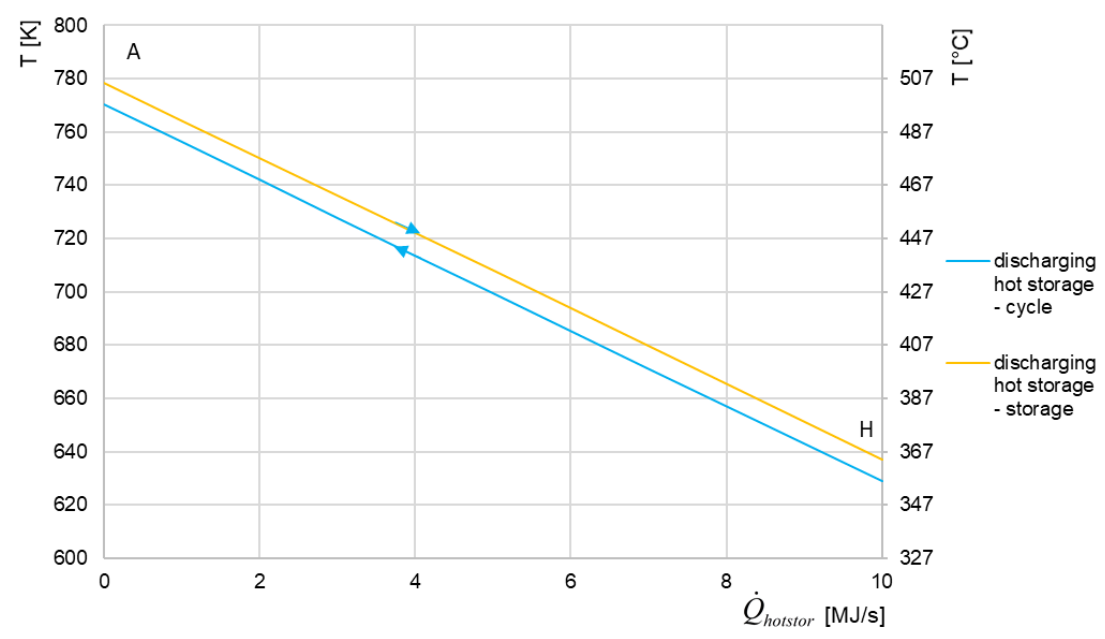

FiguRE 15. Heat transfer from the hot storage to the (discharging) cycle.

ferrable to the heat exchanger effectiveness, which is corresponding to the minimum temperature difference. The minimum temperature difference in the cycle-to-storage heat exchangers is sometimes lower than the temperature difference at the ends of the heat exchanger due to the severe pinch-point problem of $\mathrm{SCO}_{2}$ (explained in 2 and visualised for the proposed cycle in 3.2.5.

\subsubsection{HEAT EXCHANGER ANALYSIS}

The heat exchangers were checked for the pinch-point problem with the following analysis.

The hot storage heat exchanger is transferring thermal energy between the $\mathrm{CO}_{2}$ cycle and the solar salt of the storage. Figure 14 shows the charging and Figure 15 the discharging of the hot storage. The terminal temperature difference at the hot and cold ends of the heat exchanger is $8 \mathrm{~K}$ with a pinch-point of $7.5 \mathrm{~K}$ (during the charging mode). The necessary heat flux is $10 \mathrm{MJ} / \mathrm{s}$. In total, an amount of $180 \mathrm{GJ}$ thermal energy is stored in the solar salt, and 777 tons are required as a minimum to transfer the thermal energy between the two-tank storage and the charging cycle. The molten salt has a working range between $221.04^{\circ} \mathrm{C}$ (melting point) and $588.51^{\circ} \mathrm{C}$ [35], with a mean heat capacity of $1518 \mathrm{~J} / \mathrm{kgK}$ for the working temperature range of the storage [36].

Between the $\mathrm{CO}_{2}$ cycle and the thermal oil of the cold storage, a heat exchanger with pinchpoint of $7.5 \mathrm{~K}$ is used (Figures 16 17). The terminal temperature difference during the discharge operation is $18 \mathrm{~K}$. The necessary heat flux is about $6.5 \mathrm{MJ} / \mathrm{s}$. The heat capacity of the oil (THERMINOL66) is, on average, $1779 \mathrm{~J} / \mathrm{kgK}$ [37] between the heat capacity at the minimum and maximum temperatures of the heat transfer. The thermal oil is stable up to a maximum temperature of $380^{\circ} \mathrm{C} .117$ GJ of thermal energy is stored in the thermal oil, also assuming no losses through self-discharging. This amount of heat, transferred between the given temperatures, equals to 387 tons of the thermal oil.

The heat transfer in the recuperators is shown in Figure 18 to Figure 21. They have a pinch-point of $8 \mathrm{~K}$ (in the high-temperature recuperator) or greater, and 


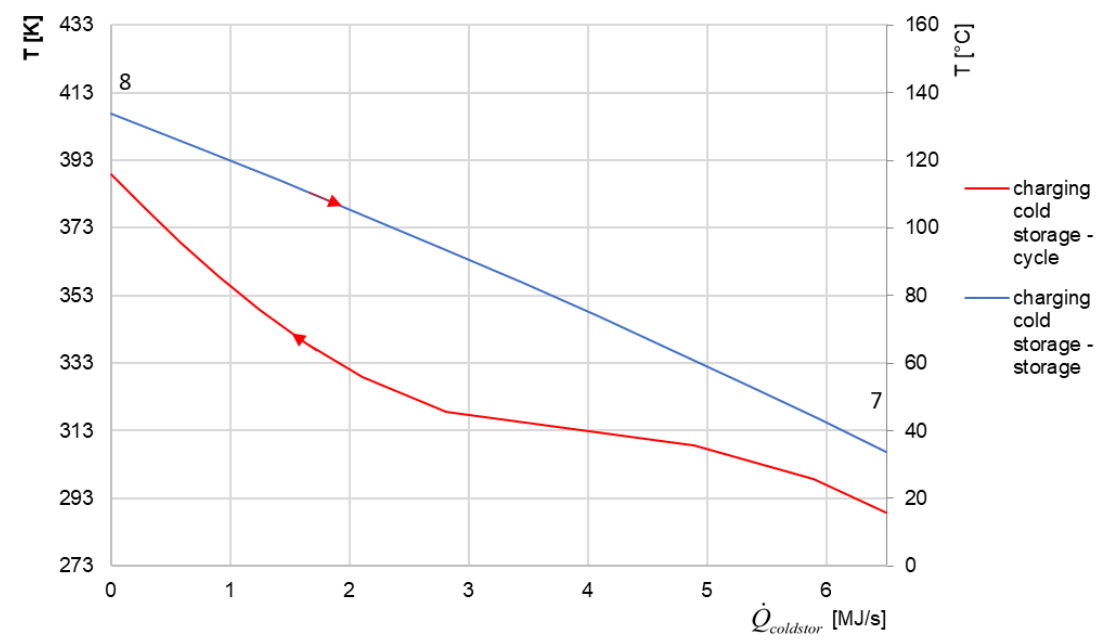

FiguRE 16. Heat transfer from the (charging) cycle to the cold storage.

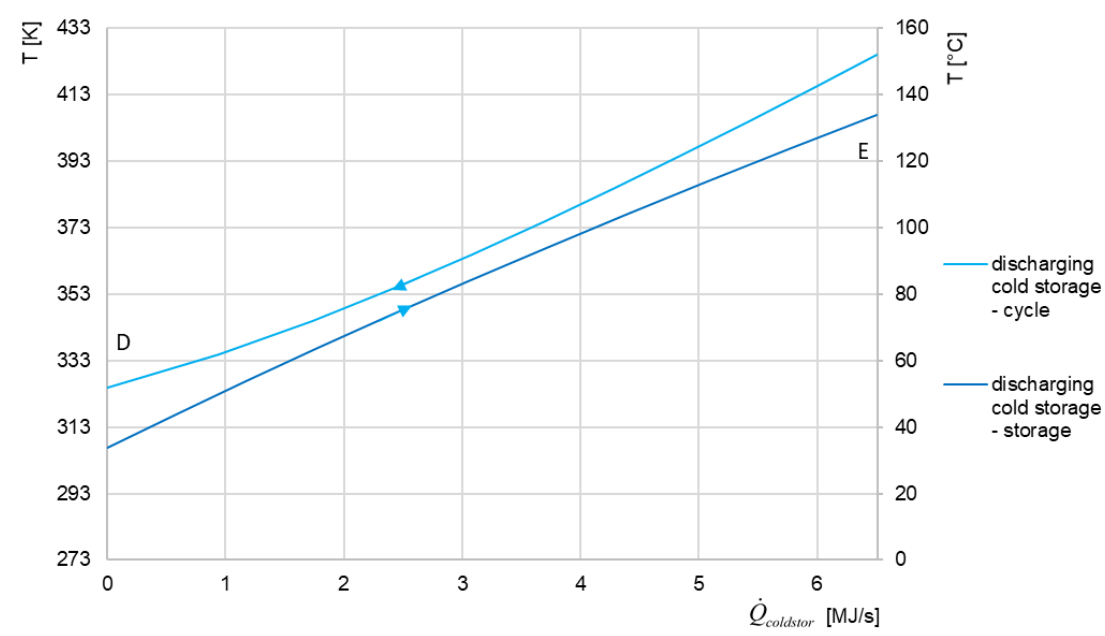

FiguRE 17. Heat transfer from the cold storage to the (discharging) cycle.

the terminal temperature difference is always higher than that, up to $43 \mathrm{~K}$.

\section{Results And Discussion}

Table 2 summarises the results of the chosen thermodynamic model. The efficiency of the discharging cycle of the PTES system $\eta_{d c}$ is $34.9 \%$, which is a little bit lower than the maximum efficiency, which can theoretically be reached without an integration in a PTES system. Such a standard supercritical $\mathrm{CO}_{2}$ Brayton cycle (without an integration in a PTES system) can reach efficiencies of about $20.5 \%$. If it is recuperated, $42.6 \%$ is possible. If it is recompressed, with a double recuperation, it can be up to $45.0 \%$ [23]. The lower efficiency of the cycle, while being integrated into a PTES system as its discharging cycle, could be explained with the boundary conditions applied to the cycle through the attached storages and due to the unavoidable rejection of the thermal energy to the environment as well as simply through the desired optimum between the high COP of the heat pump and the high efficiency of the power cycle. The heat dissipation to the environment is necessary because of the inevitable irreversibilities (entropy generation) during the charging and discharging. The coefficient of performance of the heat pump (charging cycle) $C O P_{c c}$ is 1.11 , reaching a round-trip efficiency $\eta_{r t}$ of $38.9 \%$ for the proposed system.

The pressure losses due to the heat exchange were calculated for each heat exchanger, assuming the use of shell and tube heat exchangers. The power consumption of the pumps transporting the liquid through the storages as well as the power drain of the motor and generator are neglected.

However, if we assume $\eta_{\text {generator }}=98 \%$ and $\eta_{\text {motor }}=98 \%$, while the hot storage pump reduces the net work by $W_{\text {hotstor Pump }}=10.6 \mathrm{~kW}$ and the cold storage pump by $W_{\text {coldstor Pump }}=15.9 \mathrm{~kW}$, the round-trip efficiency reduces to about $37.6 \%$ as by formula 10 . 


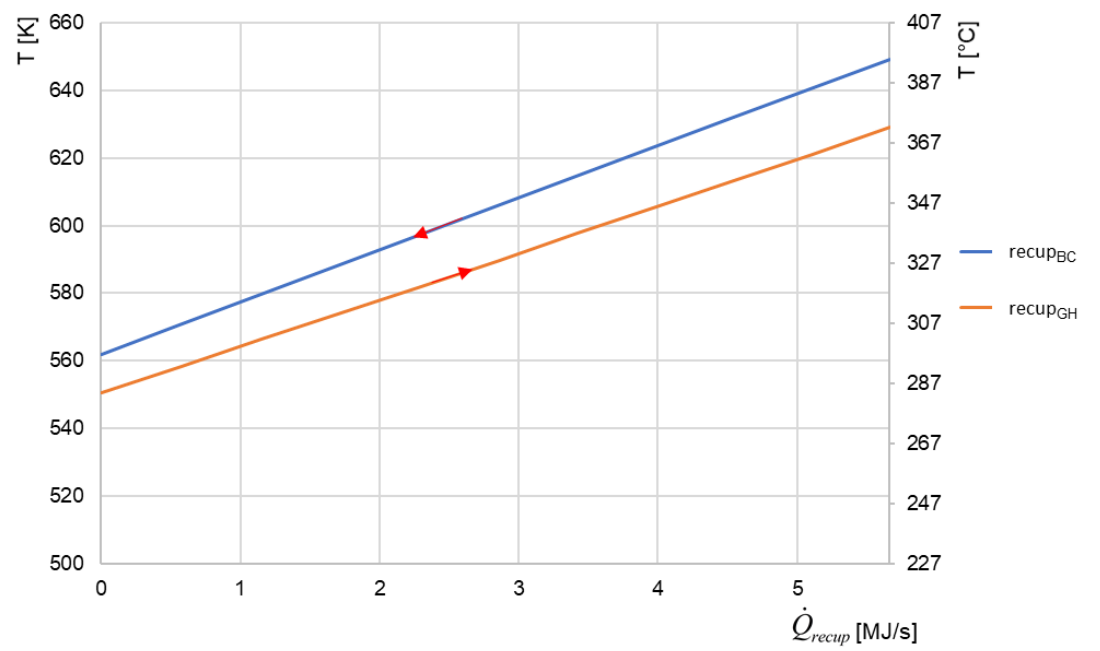

FiguRE 18. Heat transfer in the high-temperature recuperator during charging.

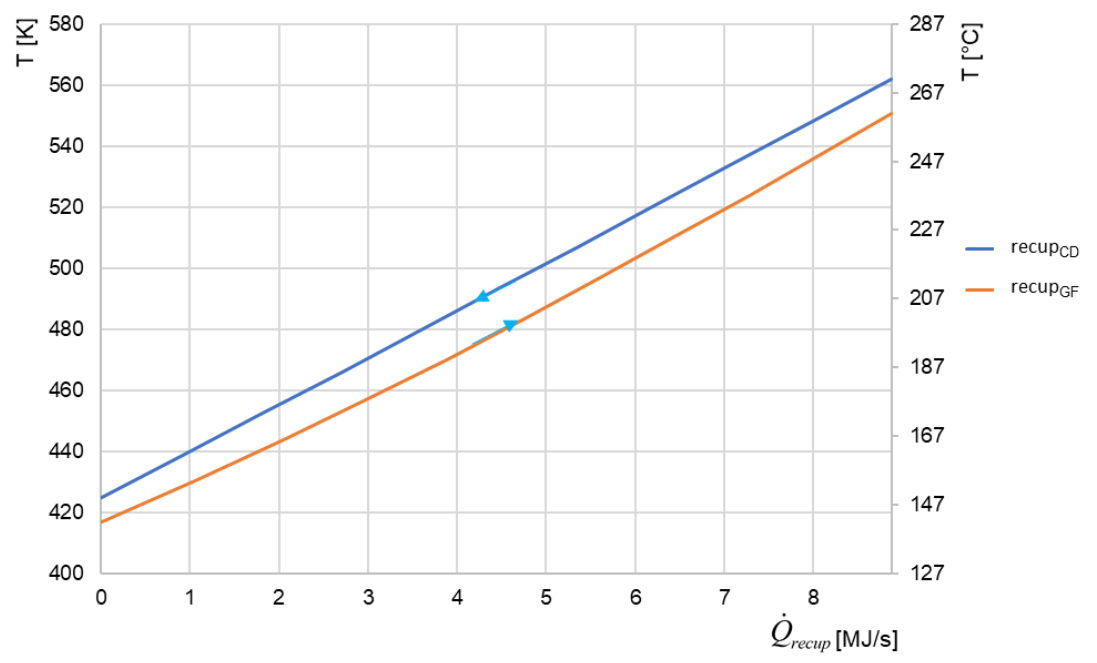

FiguRE 19. Heat transfer in the high-temperature recuperator during discharging.

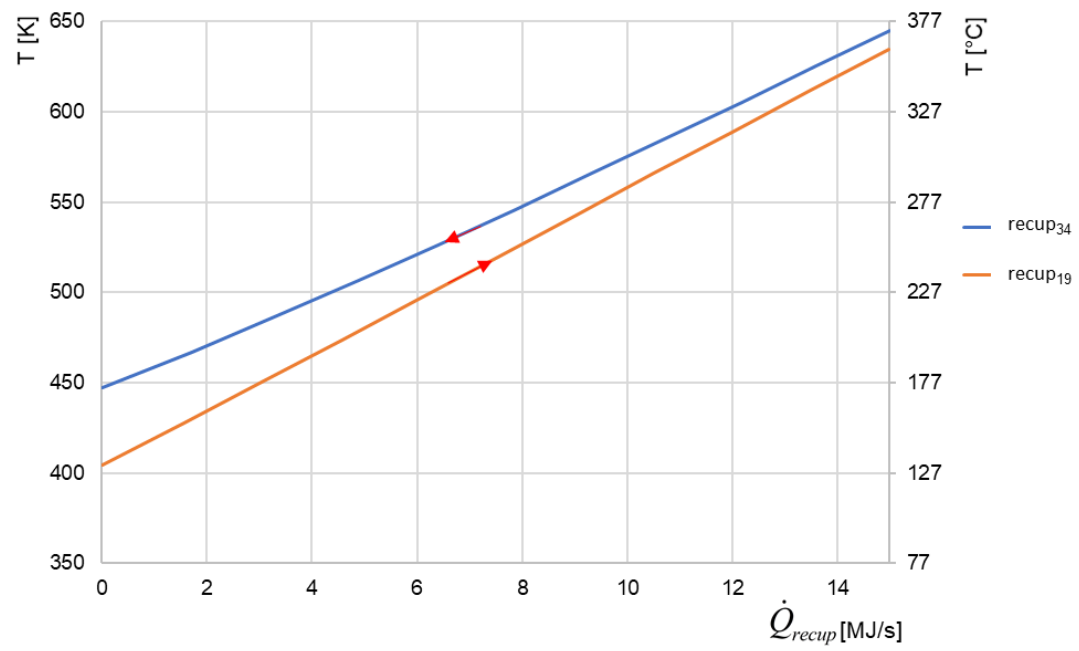

FiguRE 20. Heat transfer in the low-temperature recuperator during charging. 


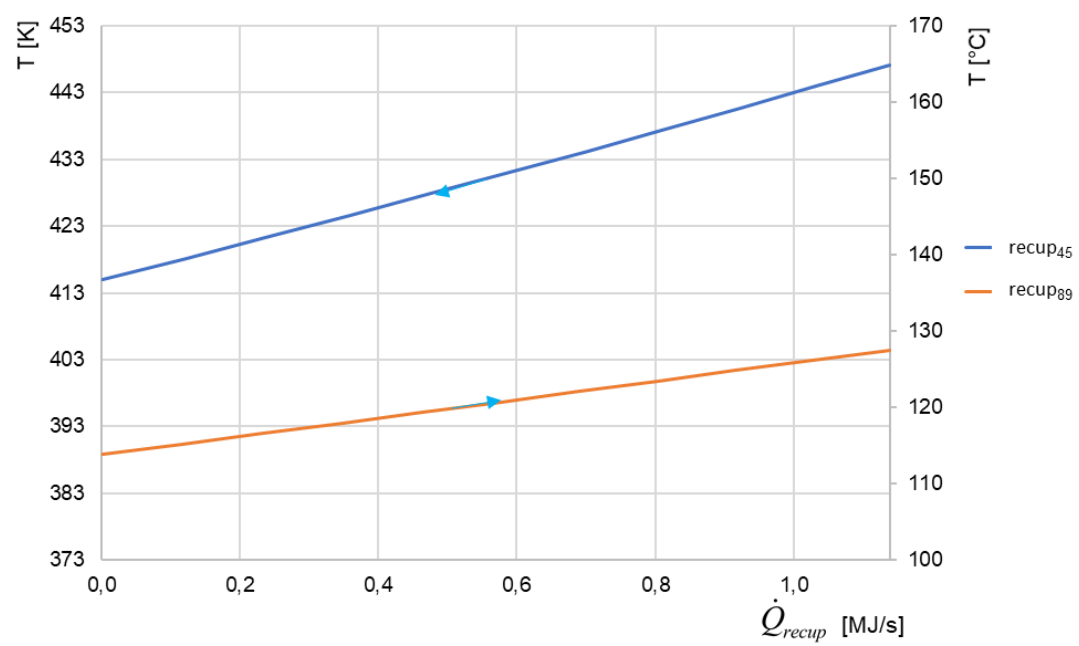

FiguRE 21. Heat transfer in the low-temperature recuperator during discharging.

$$
\eta_{\text {rt }, \text { reduced }}=\frac{\left(W_{n e t, d c}-W_{\text {storPump }}\right) \cdot \eta_{\text {gen }}}{\frac{\left(W_{n e t, c c}-W_{\text {storPump }}\right)}{\eta_{\text {mot }}}}
$$

Formula 10 can also be written as in 11, with $W_{\text {net,dc,reduced }}=W_{\text {net }, d c}-W_{\text {hotstorPump }}$ and $W_{\text {net }, c c, \text { reduced }}=W_{\text {net }, c c}-W_{\text {coldstorPump }}$.

$$
\begin{aligned}
\eta_{\text {rt }, \text { reduced }}= & \frac{W_{\text {net }, \text { dc }, \text { reduced }} \cdot \eta_{\text {gen }}}{\frac{W_{\text {net }, \text { cc }, \text { reduced }}}{\eta_{\text {mot }}}}= \\
=\frac{W_{\text {net }, \text { dc }, \text { reduced }}}{W_{\text {net }, \text { cc }, \text { reduced }}} & \eta_{\text {gen }} \cdot \eta_{\text {mot }}
\end{aligned}
$$

This allows us to express the reduced round-trip efficiency with the reduced COP of the charging cycle and the reduced efficiency of the discharging cycle (12).

$$
\eta_{r t, \text { reduced }}=C O P_{c c, \text { reduced }} \cdot \eta_{d c, \text { reduced }} \cdot \eta_{g e n} \cdot \eta_{\text {mot }}
$$

The parameters of the above-proposed cycle were chosen according to the parameter variation presented in 3.2.4 It is apparent that maximising the pressure ratio and the difference between the minimum and maximum temperature is improving not only the efficiency of the stand-alone cycle but also the overall system, although the COP of the heat pump is decreasing through these measures. If materials and costs wouldn't limit the upper temperature, this configuration could reach more than a $50 \%$ roundtrip efficiency already at $800{ }^{\circ} \mathrm{C}$, without any further changes to the original system. The lower temperature of the cycle is limited by the minimum temperature for the heat exchange with the environment. A higher turbine efficiency is, of course, resulting in a higher round-trip efficiency as well, but it is limited by the available technologies. For today's available gas $\mathrm{sCO}_{2}$ turbines, a $90 \%$ efficiency might be possible, while for the compressor, this theoretical value is most likely too high. If the compressor didn't reach such a high efficiency, the round-trip efficiency would reduce drastically, and a realisation would most likely not be feasible, especially considering the complexity of the cycle. The heat exchanger effectiveness is in a more realistic range, and it is also clear that a higher efficiency (lower temperature difference) leads to better overall results.

Because the same pressure ratio was chosen for the charging and the discharging cycles, which is only possible through the recompression, the temperatures for storing and recuperating the thermal energy are relatively fixed and the possibilities for improving the cycle efficiency are limited. This cycle configuration was, however, still chosen and analysed because it allowed the use of reciprocating devices and all heat exchangers for both the heat pump and the power cycle. For a similar cycle, with slightly different pressure ratios, recompression would not be necessary and a similar or higher round-trip efficiency could be reached.

\section{Conclusion}

This paper investigated the feasibility of a Carnotbattery with a recuperated and recompressed supercritical $\mathrm{CO}_{2}$ Brayton cycle. The pressure ratio is 3 with a low nominal pressure of $8 \mathrm{MPa}$. The system operates in a temperature range between $16{ }^{\circ} \mathrm{C}$ and $513^{\circ} \mathrm{C}$ and provides a round-trip efficiency of $38.9 \%$ with a maximum electric power output of $3.5 \mathrm{MW}$. The Carnot-battery could be attached to a small wind park (two to four wind turbines) or, for example, situated in a domestic area with a high rate of installed solar power generation. Both could charge the storage with a power of $9 \mathrm{MW}$.

$\mathrm{CO}_{2}$, in its supercritical state, can be used in a Brayton cycle as part of an energy storage system with 
a hot and cold storage. The usual measures to enhance the $\mathrm{CO}_{2}$ cycle performance are much harder to realise for a Carnot-battery, due to its complexity. The upside of a recuperated $\mathrm{sCO}_{2}$ Brayton cycle is the small turbomachinery, which is being reduced by the space needed for the heat exchangers (heat exchanger areas around 70 to $100 \mathrm{~m}^{2}$ ). Therefore, other cycle layouts, as well as other working mediums, should definitely be further investigated. Some thermal energy needs to be released to the environment to keep the energy balanced within the system. This thermal energy could be used in district heating, or for an attached ORC as it is still at a temperature of about $130^{\circ} \mathrm{C}$. The modelled system provides a round-trip efficiency of $38.9 \%$. For such a complex system, with recompression and double recuperation, this round-trip efficiency is comparably low. Simpler configurations of $\mathrm{sCO}_{2}$ Brayton cycles might reach the same or higher efficiencies, as also the analysis of McTigue et al. in 2019 suggests. They proposed a simple $\mathrm{sCO}_{2}$ Brayton cycle, which could reach up to $60.4 \%$ with a low-temperature cycle $\left(200^{\circ} \mathrm{C}\right)$ and $78.4 \%$ with a high-temperature cycle $\left(560^{\circ} \mathrm{C}\right)$. They're mentioning that a recuperation would be feasible due to the high-temperature difference between the compression and the expansion, but they didn't analyse it. This paper, however, shows that a recuperation is difficult to implement and might actually not improve the round-trip efficiency of a $\mathrm{sCO}_{2}$ Brayton PTES as expected due to the limitations of the integration in the storage system.

\section{LIST OF SYMBOLS}

Abbreviations

CHEST Compressed Heat Energy Storage

$\mathrm{CO}_{2}$ Carbon Dioxide

$C O P$ Coefficient Of Performance

$E S$ Energy storages

ETES Electro-Thermal Energy Storage

ORC Organic Rankine Cycle

P2H2P Power-to-Heat-to-Power

$P C M$ Phase Change Material

PHES Pumped Heat Energy Storage

PTES Pumped Thermal Energy Storage

TES Thermal Energy Storages

\section{Symbols}

$h$ Specific enthalpy $[\mathrm{kJ} / \mathrm{kg}]$

$\dot{m}$ Mass flow $[\mathrm{kg} / \mathrm{s}]$

$P R$ Pressure ratio

$Q$ Heat [J]

$\dot{Q}$ Heat flow rate $[\mathrm{J} / \mathrm{s}=\mathrm{W}]$

$s \quad$ Specific Entropy $\left[\mathrm{J} /\left(\mathrm{kg}^{*} \mathrm{~K}\right)\right]$

$t$ Time (e. g. discharging time $\mathrm{t}_{\text {discharge }}$ ) [s]

$T$ Temperature $\left[{ }^{\circ} \mathrm{C}\right]$

$W$ Work rate (power) [W]

$\eta \quad$ Isentropic efficiency

\section{Subscripts}

$a m b$ Ambient

cc Charging cycle

coldstor Cold storage

comp Compression

dc Discharging cycle

exp Expansion

gen generator

hotstor Hot storage

in "in", as added to the cycle

mot motor

out "out", as extracted from the cycle

recup Recuperation/recuperated

$r t$ Round-trip

stor Storage

$1,2,3, \ldots$ Cycle state points during charging

$A, B, C, \ldots$ Cycle state points during discharging

\section{ACKNOWLEDGEMENTS}

This work was supported by the Grant Agency of the Czech Technical University in Prague, grant No. SGS20/116/OHK2/2T/12.

\section{REFERENCES}

[1] A. B. Gallo, et al. Energy storage in the energy transition context: A technology review. Renewable and Sustainable Energy Reviews 65:800-822, 2016. https://doi.org/10.1016/j.rser.2016.07.028

[2] Global Modeling And Assimilation Office, S. Pawson. inst3_3d_asm_Cp: MERRA 3D IAU state, meteorology instantaneous 3-hourly (p-coord, $1.25 \times 1.25 \mathrm{~L} 42)$ version 5.2.0, 2008.

[3] Global Modeling And Assimilation Office, S. Pawson. inst6_3d_ana_Np: MERRA 3D analyzed state, meteorology instantaneous 6-hourly (p-coord, $2 / 3 \times 1 / 2 \mathrm{~L} 42)$ version $5.2 .0,2008$.

[4] Global Modeling And Assimilation Office, S. Pawson. tavg1_2d slv_Nx: MERRA 2D IAU diagnostic, single level meteorology, time average 1 -hourly $(2 / 3 \times 1 / 2 \mathrm{~L} 1)$ version 5.2.0, 2008.

[5] Global Modeling And Assimilation Office, S. Pawson. MERRA-2 tavg1_2d_rad_Nx: 2d, 1-hourly, time-averaged, single-level, assimilation, radiation diagnostics v5.12.4, 2015.

[6] M. Söllch. Netzrelevante Daten. [2021-07-14], https://web.archive.org/web/20160821034950/ https://www.main-donau-netz.de/header/ veroeffentlichungen/strom/netzrelevantedaten.html

[7] S. Pawson. GMAO MERRA: Modern era retrospective-analysis for research and applications. [2020-03-05], https://disc.gsfc.nasa.gov/.

[8] IEA, International Energy Agency. Technology roadmap energy storage, 2014. 
[9] X. Wang, et al. Investigation of thermodynamic performances for two-stage recompression supercritical $\mathrm{CO}_{2}$ Brayton cycle with high temperature thermal energy storage system. Energy Conversion and Management 165:477-487, 2018. https://doi.org/10.1016/j.enconman.2018.03.068

[10] V. Novotný. Pumped thermal energy storage (Carnot batteries): Overview and prospects.

[11] A. Valera-Medina, et al. Ammonia for power. Progress in Energy and Combustion Science 69:63-102, 2018. https://doi.org/10.1016/j.pecs.2018.07.001

[12] T. Barmeier. Electric thermal energy storage (ETES). [2020-08-16], https :

//windenergietage.de/wp-content/uploads/sites/ 2/2017/11/26WT0811_F11_1120_Dr_Barmeier.pdf

[13] The Engineer. Team connects first grid-scale pumped heat energy storage system. [2020-08-13], https://www. theengineer.co.uk/grid-scalepumped-heat-energy-storage/

[14] J. Howes. Concept and development of a pumped heat electricity storage device. Proceedings of the IEEE 100(2):493-503, 2012. https://doi.org/10.1109/JPROC.2011.2174529

[15] Siemens Gamesa Renewable Energy, S.A. Start of construction in Hamburg-Altenwerder: Siemens Gamesa to install FES heat-storage for wind energy.

[2020-08-13], https://www.siemensgamesa.com/enint/newsroom/2017/11/start-of-construction-inhamburg-altenwerder

[16] Siemens Gamesa Renewable Energy, S.A. World first: Siemens Gamesa begins operation of its innovative electrothermal energy storage system. [2020-08-13], https://www.siemensgamesa.com/enint/newsroom/2019/06/190612-siemens-gamesainauguration-energy-system-thermal.

[17] Siemens Gamesa Renewable Energy, S.A. Thermal energy storage with ETES I Siemens Gamesa. [2020-08-13], https://www. siemensgamesa.com/enint/products-and-services/hybrid-andstorage/thermal-energy-storage-with-etes

[18] O. Dumont, et al. Carnot battery technology: A stateof-the-art review. Journal of Energy Storage 32:101756, 2020. https://doi.org/10.1016/j.est.2020.101756

[19] O. Dumont, V. Lemort. First experimental results of a thermally integrated carnot battery using a reversible heat pump/organic rankine cycle. In 2nd International Workshop on Carnot Batteries 2020. 2020.

https://www.researchgate.net/publication/ 344252650_First_Experimental_Results_of_a_ Thermally_Integrated_Carnot_Battery_Using_a_ Reversible_Heat_Pump_Organic_Rankine_Cycle

[20] R. Morgan, et al. Liquid air energy storage analysis and first results from a pilot scale demonstration plant. Applied Energy 137:845-853, 2015. https://doi.org/10.1016/j.apenergy.2014.07.109.

[21] Highview Power. Plants: Pilot plant. [2020-10-26], https://highviewpower.com/plants/

[22] Schick GmbH + Co. KG. R744 / $\mathrm{CO}_{2}$ : Kohlendioxid: Ein unbegrenzt verfügbarer und natürlicher Stoff. [2020-08-10], https :

//www.schickgruppe.de/WordPress/?page_id=1103
[23] K. Brun, et al. Fundamentals and applications of supercritical carbon dioxide $\left(\mathrm{sCO}_{2}\right)$ based power cycles. Woodhead Publishing an imprint of Elsevier, Duxford, United Kingdom, 2017.

[24] S. Weihe, et al. Untersuchung zur Evaluierung von Forschungspotentialen hinsichtlich Prozessen,

Komponenten und Werkstoffen von trans- und superkritischen $\mathrm{CO}_{2}$-Anwendungen. [2020-08-17], http://www.zfes.uni-stuttgart.de/downloads/ Bericht_ZfES_MPA_ITSM_IKE.pdf.

[25] M. Morandin, et al. Thermo-electrical energy storage: a new type of large scale energy storage based on thermodynamic cycles. [2020-08-17], https://www.researchgate.net/publication/ 259973612_Thermoelectric_energy_storage_a_new_ type_of_large_scale_energy_storage_based_on_ thermodynamic_cycles.

[26] M. Mercangöz, et al. Electrothermal energy storage with transcritical $\mathrm{CO}_{2}$ cycles. Energy 45(1):Energy, 2012. https://doi.org/10.1016/j.energy . 2012.03.013.

[27] Y. M. Kim, et al. Transcritical or supercritical $\mathrm{CO}_{2}$ cycles using both low- and high-temperature heat sources. Energy 43(1):402-415, 2012. https://doi.org/10.1016/j.energy . 2012.03.076

[28] F. Ayachi, et al. Thermo-electric energy storage involvingl $\mathrm{CO}_{2}$ transcritical cycles and ground heat storage. Applied Thermal Engineering 108:1418-1428, 2016. https: //doi.org/10.1016/j.applthermaleng.2016.07.063.

[29] W.-D. Steinmann, H. Jockenhöfer, D. Bauer. Thermodynamic analysis of high-temperature carnot battery concepts. Energy Technology 8(3):1900895, 2020. https://doi.org/10.1002/ente. 201900895

[30] J. McTigue, et al. Pumped thermal electricity storage with supercritical $\mathrm{CO}_{2}$ cycles and solar heat input. AIP Conference Proceedings 2303(1):190024, 2020. https://doi.org/10.1063/5.0032337

[31] Y.-M. Kim, et al. Isothermal transcritica $\mathrm{CO}_{2}$ cycles with TES (thermal energy storage) for electricity storage. Energy 49:484-501, 2013. https://doi.org/10.1016/j.energy.2012.09.057.

[32] M. Morandin, et al. Thermoeconomic design optimization of a thermo-electric energy storage system based on transcritical $\mathrm{CO}_{2}$ cycles. Energy 58:571-587, 2013.

https://doi.org/10.1016/j.energy.2013.05.038

[33] l. V. Dosta, et al. A supercritical carbon dioxide cycle for next generation nuclear reactors. [2021-07-14], https://web.mit.edu/22.33/www/dostal.pdf

[34] G. Angelino. Carbon dioxide condensation cycles for power production. Journal of Engineering for Power 90(3):287-295, 1968. https://doi.org/10.1115/1.3609190

[35] A. G. Fernández, et al. Thermal characterization of HITEC molten salt for energy storage in solar linear concentrated technology. Journal of Thermal Analysis and Calorimetry 122(1):3-9, 2015. https://doi.org/10.1007/s10973-015-4715-9. 
[36] SQM International N.V. Thermo-solar salts. [2020-08-21], https://www.sqm.com/wp-content/ uploads/2018/05/Solar-salts-Book-eng.pdf.

[37] Solutia. THERMINOL 66: High performance highly stable heat transfer fluid. [2020-03-11], http://twt.mpei.ac.ru/TTHB/HEDH/HTF-66.PDF

[38] E. Lemmon. NIST reference fluid thermodynamic and transport properties database: Version 9.0, NIST standard reference database 23 . https://doi.org/10.18434/T4JS3C

[39] K. Attonaty, et al. Thermodynamic analysis of a 200 mwh electricity storage system based on high temperature thermal energy storage. Energy 172:1132-1143, 2019.

https://doi.org/10.1016/j.energy . 2019.01.153. 